\title{
STUDIES ON THE MACROLIDE ANTIBIOTIC YL-704 COMPLEX.* IV
}

THE STRUCTURES OF MINOR COMPONENTS

\author{
Akio Kinumaki, Isao Takamori, Yoichi Sugawara, Yoshiaki Seki, \\ Makoto SuzUKI and TOMOHARU OKUdA \\ Microbial Chemistry Research Laboratory, \\ Tanabe Seiyaku Co., Ltd., Toda, Saitama, Japan \\ (Received for publication July 18, 1973)
}

\begin{abstract}
The structures of minor components of new macrolide YL-704, which were produced by Streptomyces platensis subsp. malvinus MCRL 0388, were elucidated by the physicochemical analyses and the oxidation reaction, and the mass spectrometry of their acetyl derivatives.

The presence of $\alpha, \beta, \gamma, \delta$-dienone and $\alpha, \beta$-unsaturated $\gamma, \delta$-epoxy alcohol chromophore was observed in aglycone portions of minor components, in addition to $\alpha, \beta, \gamma, \delta$ unsaturated alcohol system such as YL-704 $\mathrm{A}_{1}$ and $\mathrm{B}_{1}$.

Furtheremore, at the C-3 position in aglycone part, acetyloxy, propionyloxy and butylyloxy functions were determined together with several acyl groups at the end sugar parts.
\end{abstract}

The eleven minor components of macrolide antibiotic YL-704 were isolated from the culture broth of Streptomyces platensis subsp. malvinus MCRL 0338. ${ }^{1)}$ The minor components were studied for the elucidation of their structures ${ }^{2)}$ by comparison to the major components YL-704 $\mathrm{A}_{1}$ and $\mathrm{B}_{1}{ }^{\left.3{ }^{3}, 4\right)}$ They were classified into three groups based on the characteristic UV absorption. The first group with the UV maximum at $280 \mathrm{~nm}$ which indicated the $\alpha, \beta, \gamma, \delta$-dienone chromophore contained $\mathrm{YL}-704 \mathrm{~W}_{1}$ and $\mathrm{W}_{2}$. The second group involved YL-704 $\mathrm{A}_{0}, \mathrm{~A}_{2}, \mathrm{~A}_{3}, \mathrm{~B}_{2}, \mathrm{~B}_{3}$ and $\mathrm{C}_{2}$ with the $232 \sim 235 \mathrm{~nm}$ maximum absorption of the $\alpha, \beta, \gamma, \delta$-unsaturated alcohol system such as YL-704 $\mathrm{A}_{1}, \mathrm{~B}_{1}$ and leucomycins. The third group which did not present the particular UV absorption included YL-704 $\mathrm{C}_{1}, \mathrm{C}_{3}$ and $\mathrm{C}_{4}$. The first group components gave mono acetates, the second and the third produced diacetates by total acetylation.

(1) YL-704 $\mathrm{W}_{1}$ and $\mathrm{W}_{2}$ :

The analogous IR spectra of YL-704 $\mathrm{W}_{1}$ and $\mathrm{W}_{2}$ suggested the functional groups of hydroxy (3550, $\left.3410 \mathrm{~cm}^{-1}\right)$, aldehyde $\left(2750 \mathrm{~cm}^{-1}\right)$, lactone and ester $\left(1748,1737 \mathrm{~cm}^{-1}\right)$, carbonyl $\left(1690 \mathrm{~cm}^{-1}\right)$

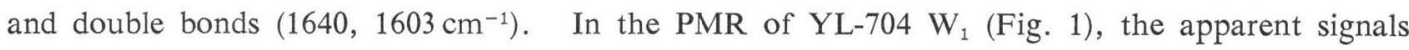
were $\delta\left(\mathrm{CDCl}_{3}\right) \quad 0.90 \sim 1.35\left(7 \times \mathrm{CH}_{3}-\mathrm{C}\right), 2.53\left(-\mathrm{N}\left(\mathrm{CH}_{3}\right)_{2}\right), 3.57\left(-\mathrm{OCH}_{3}\right), 6.05-6.43$ (olefinic $4 \mathrm{H})$ and $9.54(-\mathrm{CHO})$.

Besides, the acetyl methyl protones of carbomycin $\mathrm{B}^{5)}$ and the double doublet $(9-\mathrm{H})$ at 4.13 ppm of leucomycin $\mathrm{A}_{3}{ }^{8)}$ were lacked. YL-704 $\mathrm{W}_{2}$ showed the same functional groups in PMR to $\mathrm{YL}-704 \mathrm{~W}_{1}$.

The both components gave the monoacetates. The mass spectrum of acetyl YL-704 $\mathrm{W}_{1}$ was shown in Fig. 2, and the spectrum of acetyl YL-704 $\mathrm{W}_{2}$ was similar except the fragment peaks containing the aglycone portion. The mass fragmentation patterns of them were identical

* Hereafter, we wish to propose the name,- platenomycin, in place of the antibiotic YL-704. 
with the sugar parts of acetyl carbomycin $\mathrm{B}$ and different from the aglycone peaks $\left(\mathrm{AGL}^{+}\right)$of acetyl carbomycin $\mathrm{B}$. The $\mathrm{AGL}^{+}$peaks of the acetyl YL-704 $\mathrm{W}_{1}$ and the acetyl YL-704 $\mathrm{W}_{2}$ were $m / e 421$ and $m / e$ 435, respectively, those were larger by 14 and 28 mass units than the $\mathrm{AGL}^{+}\left(m / e\right.$ 407) of acetyl carbomycin B. On the other hand, $\mathrm{AGL}^{+}$- acyloxy fragments of these three compounds were $m / e 347$ equally.

At the aglycone C-3 position, the presence of the propionyloxy function and the butylyloxy function were concluded for $\mathrm{YL}-704 \mathrm{~W}_{1}$ and $\mathrm{W}_{2}$, respectively. Structurally, YL-704 $\mathrm{W}_{1}$ was identified to be dehydro YL-704 $\mathrm{A}_{1}$ by $\mathrm{MnO}_{2}$ oxidation.

(2) YL-704 $\mathrm{A}_{0}, \mathrm{~A}_{2}, \mathrm{~A}_{3}, \mathrm{~B}_{2}, \mathrm{~B}_{3}$ and $\mathrm{C}_{2} *$ :

The IR spectra of YL-704 $\mathrm{A}_{2}, \mathrm{~A}_{3}, \mathrm{~B}_{2}, \mathrm{~B}_{3}$ and $\mathrm{C}_{2}$ suggested the presence of same functional groups as YL-704 $A_{1}$ and $B_{1}$, particularly, in YL-704 $A_{3}, B_{3}$ and $C_{2}$ the absorption at $1235 \mathrm{~cm}^{-1}$ was observed strongly. $\mathrm{YL}-704 \mathrm{~A}_{0}$ was measured as diacetyl derivative which was assumed to be like diacetyl YL-704 $\mathrm{A}_{1}{ }^{3,4}$ YL-704 $\mathrm{A}_{2}$ and $\mathrm{B}_{2}$ showed the same UV maximum at $235 \mathrm{~nm}$

Fig. 1. PMR spectrum of YL-704 $\mathrm{W}_{1}$

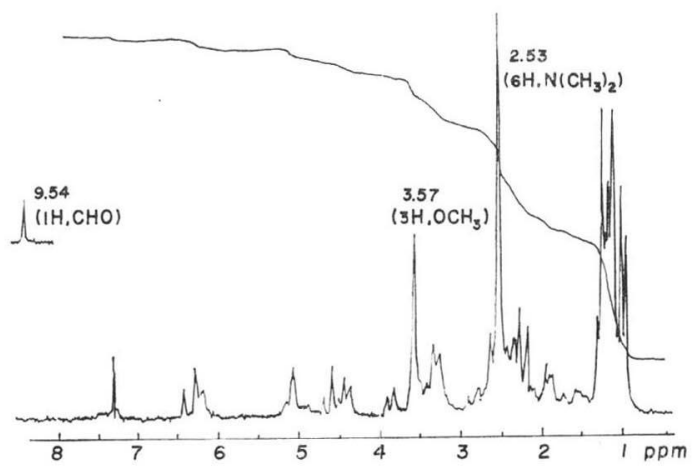
of $\log \varepsilon 4.34$ and $\log \varepsilon 4.30$. In mass spectrometry, diacetyl YL-704 $\mathrm{A}_{2}\left[\mathrm{~m} / \mathrm{e} 925\left(\mathrm{M}^{+}\right), 465\right.$ $\left.\left(\mathrm{AGL}^{+}\right), 444\left(\mathrm{ADS}^{+}\right)\right]$and diacetyl YL-704 $\mathrm{B}_{2}$ [m/e $\left.897\left(\mathrm{M}^{+}\right), 465\left(\mathrm{AGL}^{+}\right), 416\left(\mathrm{ADS}^{+}\right)\right]$were. suggested the similarity to diacetyl YL-704 $\mathrm{A}_{1}$ and $\mathrm{B}_{1}$, respectively. The olefinic protons of of YL-704 $\mathrm{A}_{2}$ (Fig. 3) and $\mathrm{B}_{2}$ at $6.0 \sim 6.5 \mathrm{ppm}$ in PMR were complex and the same pattern as in the allylic rearranged demycarosyl YL704 A $_{1}$ II. ${ }^{4)}$

Those were suggested to be artifacts of YL-704 $A_{1}$ and $B_{1}$ owing to the uncertain yield of each production. At the treatment

Fig. 2. Mass spectrum of acetyl YL-704 $\mathrm{W}_{1}$

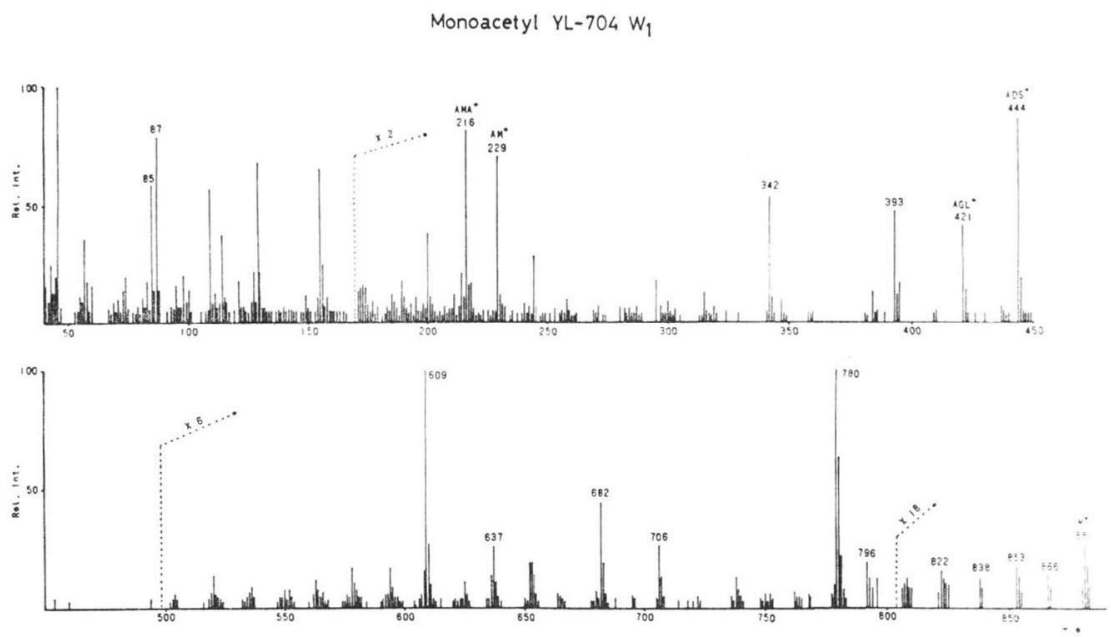

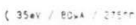

* YL-704 $\mathrm{C}_{2}$ was assumed to be same as espinomycin II. ${ }^{7}$ 
of YL-704 $A_{1}$ and $B_{1}$ with $\mathrm{pH} 4$ water, the new products were identified to be YL-704 $A_{2}$ and $B_{2}$ on TLC, respectively. Therefore, YL-704 $A_{2}$ and $B_{2}$ were decided to be the $C-9 \sim C-13$ allylic hydroxy rearranged compounds of YL-704 $\mathrm{A}_{1}$ and $\mathrm{B}_{1}$.

The UV maximum of YL-704 $\mathrm{A}_{0}, \mathrm{~A}_{3}, \mathrm{~B}_{3}$ and $\mathrm{C}_{2}$ were observed at $232 \mathrm{~nm}$ such as YL-704 $A_{1}$. The each structure of their acetates was successfully estimated by the mass spectrometry.

Diacetyl YL-704 $\mathrm{A}_{0}$ showed m/e $939\left(\mathrm{M}^{+}\right), 479\left(\mathrm{AGL}^{+}\right), 419\left(\mathrm{AGL}^{+}-\mathrm{CH}_{3} \mathrm{COOH}\right), 331\left(\mathrm{AGL}^{+}\right.$ $\left.-\mathrm{CH}_{3} \mathrm{COOH}-\mathrm{CH}_{3} \mathrm{CH}_{2} \mathrm{CH}_{2} \mathrm{COOH}\right)$ and $444\left(\mathrm{ADS}^{+}\right)$, of which the $\mathrm{AGL}^{+}$was larger by 14 mass units than that of diacetyl YL-704 $\mathrm{A}_{1}$, and $m / e 331$ and $\mathrm{ADS}^{+}$were common to each other. It was concluded that the butylyloxy function was displaced instead of propionyloxy in the aglycone of YL-704 $\mathrm{A}_{1}$, moreover, the acyl disaccharide was same as YL-704 $\mathrm{A}_{1}$.

The aglycone peaks of diacetyl YL-704 $\mathrm{A}_{3}$ and $\mathrm{B}_{3}$ were both $\mathrm{m} / \mathrm{e} 451$, and then they were identical to that of diacetyl leucomycin $\mathrm{A}_{3}$. The $\mathrm{ADS}^{+} \mathrm{s}$ were measured to be $m / e 444$ and $m / e$ 416, which suggested the same sugar parts as YL-704 $\mathrm{A}_{1}$ and $\mathrm{B}_{1}$, respectively. YL-704 $\mathrm{A}_{3}$ and $\mathrm{B}_{3}$ were identified to be leucomycin $\mathrm{A}_{3}$ and $\mathrm{A}_{6},{ }^{8}$ respectively, by m.p., TLC, IR and PMR. YL-704 $\mathrm{C}_{2}$ showed an acetyl methyl signal at $2.18 \mathrm{ppm}$ in PMR and the aglycone peak of diacetyl YL-704 $\mathrm{C}_{2}$ was $m / e 465$ such as YL-704 $\mathrm{A}_{1}$, and $\mathrm{ADS}^{+}$showed $m / e$ 402. Consequently, the terminal acyl group of sugar part was the acetyl function.

(3) YL-704 $\mathrm{C}_{1}, \mathrm{C}_{3}$ and $\mathrm{C}_{4}{ }^{*}$ :

The components of this group showed the similar IR spectra to YL-704 $\mathrm{A}_{1}$, in addition to

Fig. 3. PMR spectrum of YL-704 $A_{2}$

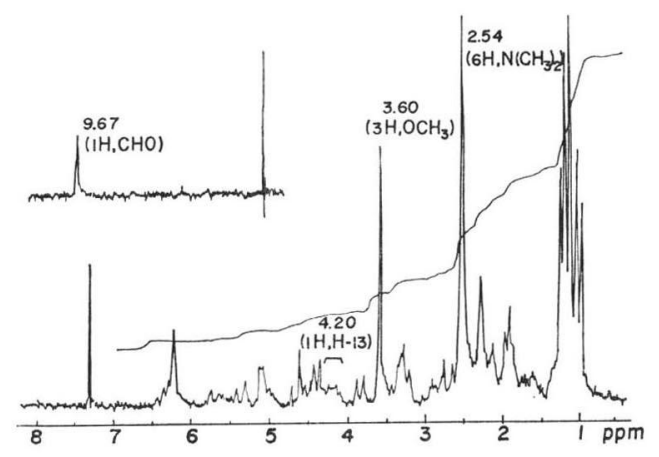

Fig. 4. PMR spectrum of YL-704 $\mathrm{C}_{1}$

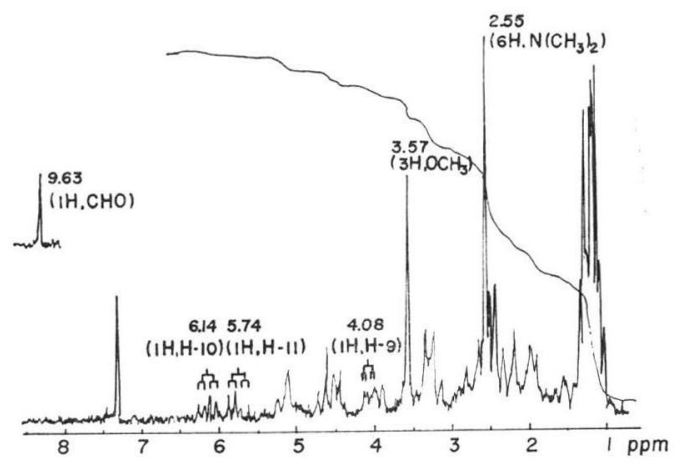

the characteristic UV of the end absorption. However, YL-704 $\mathrm{C}_{4}$ was assumed to contain an acetyl group by $1235 \mathrm{~cm}^{-1}$ absorption. From the PMR spectrum of YL-704 $\mathrm{C}_{1}$ (Fig. 4), the olefinic protons were $5.74 \mathrm{ppm}(1 \mathrm{H}$, $\mathrm{d}, \mathrm{d}, \mathrm{J}=9, \quad 15 \mathrm{~Hz})$ and $6.14 \mathrm{ppm}(1 \mathrm{H}, \mathrm{d}, \mathrm{d}$, $\mathbf{J}=8, \quad 15 \mathrm{~Hz}$ ) which suggested the partial structure of $-\mathrm{HC}-\mathrm{CH}=\mathrm{CH}-\mathrm{CH}-. \quad \mathrm{YL}-704$ $\mathrm{C}_{3}$ and $\mathrm{C}_{4}$ were analogous to YL-704 $\mathrm{C}_{1}$ by the physicochemical behaviors.

The mass spectra of diacetyl YL-704 $\mathrm{C}_{1}$ (Fig. 5), $\mathrm{C}_{3}$ and $\mathrm{C}_{4}$ were analogous to other YL-704 components, in which $\mathrm{AGL}^{+} \mathrm{s}$ were $m / e 481$ for diacetyl YL-704 $\mathrm{C}_{1}$ and $\mathrm{C}_{3}$ and m/e 467 for diacetyl YL-704 $\mathrm{C}_{4}$ which were larger by one oxygen than diacetyl YL-704 $\mathrm{A}_{1}$ and diacetyl leucomycin $\mathrm{A}_{3}$, respectively. The $\operatorname{ADS}^{+}\left(m / e\right.$ 416) of diacetyl YL-704 $\mathrm{C}_{1}$ was identical with diacetyl YL-704 $\mathrm{B}_{1}$ and those (m/e 444) of diacetyl YL-704 $\mathrm{C}_{3}$ and $\mathrm{C}_{4}$ suggested the same terminal acyl group as YL-704 A $\mathrm{A}_{1}$. m/e 347 ( $\mathrm{AGL}^{+}-\mathrm{CH}_{3} \mathrm{COOH}-\mathrm{CH}_{3}$ $\mathrm{COOH}$ and $\mathrm{AGL}^{+}-\mathrm{CH}_{3} \mathrm{COOH}-\mathrm{CH}_{3} \mathrm{CH}_{2}-$

\footnotetext{
* YL-704 $\mathrm{C}_{1}, \mathrm{C}_{3}$ and $\mathrm{C}_{4}$ were found to be identical with maridomycin III, I and II, ${ }^{\text {9) }}$ respectively.
} 
$\mathrm{COOH}$ ) was common to the three compounds of this group, which was larger by one oxygen than $m / e 331$ of diacetyl YL-704 $\mathrm{A}_{1}$ and $\mathrm{B}_{1}$.

The oxidation of YL-704 $\mathrm{C}_{1}$ with $\mathrm{MnO}_{2}$ in $\mathrm{CHCl}_{3}$ gave one dehydro derivative, $\alpha, \beta$ unsaturated $\gamma, \delta$-epoxy ketone with the UV maximum at $239 \mathrm{~nm}$ same as carbomycin $\mathrm{A}^{10)}$ The aglycone chromophore of this group was deduced to be $\alpha, \beta$-unsaturated $\gamma, \delta$-epoxy alcohol.

Fig. 5. Mass spectrum of diacetyl YL-704 $\mathrm{C}_{1}$
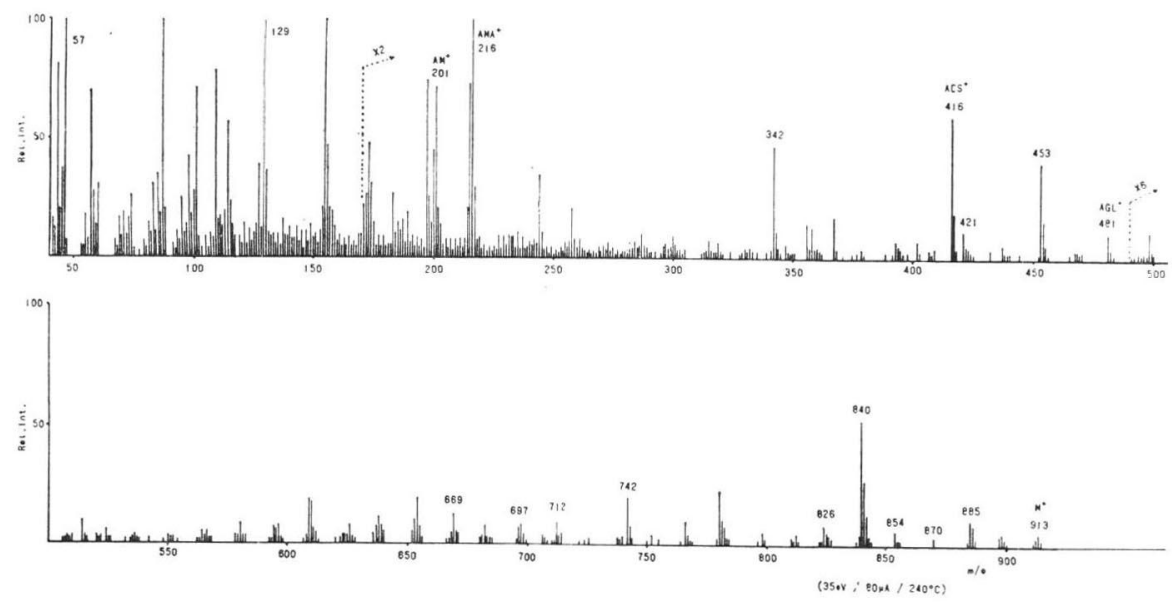

Table 1. Structures of minor components and diagnostic fragment peaks $(\mathrm{m} / \mathrm{e})$ of their acetates $\left(9,2^{\prime}\right.$-diacetate/I, III and $2^{\prime}$-acetate/II, IV)

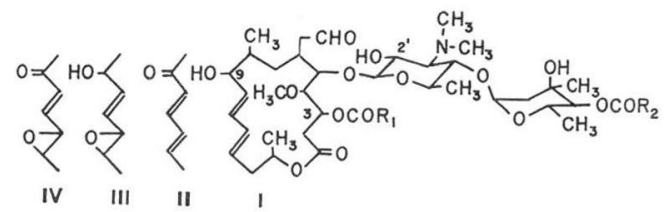

\begin{tabular}{|c|c|c|c|c|c|c|c|c|c|}
\hline Acetate & $\begin{array}{l}\text { Chromo- } \\
\text { phore }\end{array}$ & $\mathrm{R}_{1}$ & $\mathrm{R}_{2}$ & $\mathrm{M}^{+}$ & $\mathrm{AGL}^{+}$ & $\begin{array}{l}\mathrm{AGL}^{+} \\
-9 . \mathrm{Ac} \\
-\mathrm{R}_{1} \mathrm{COOH} \\
\end{array}$ & $\mathrm{ADS}+$ & $\mathrm{AMA}^{+}$ & $\mathrm{AM}^{+}$ \\
\hline YL-704 $\mathrm{A}_{0}$ & I & $-\mathrm{CH}_{2} \mathrm{CH}_{2} \mathrm{CH}_{3}$ & $-\mathrm{CH}_{2} \mathrm{CH}\left(\mathrm{CH}_{3}\right)_{2}$ & 939 & 479 & 331 & 444 & 216 & 229 \\
\hline YL-704 $\mathrm{C}_{2}$ & I & $-\mathrm{CH}_{2} \mathrm{CH}_{3}$ & $-\mathrm{CH}_{3}$ & 883 & 465 & 331 & 402 & 216 & 187 \\
\hline YL-704 $A_{3}$ & I & $-\mathrm{CH}_{3}$ & $-\mathrm{CH}_{2} \mathrm{CH}\left(\mathrm{CH}_{3}\right)_{2}$ & 911 & 451 & 331 & 444 & 216 & 229 \\
\hline YL-704 B & I & $-\mathrm{CH}_{3}$ & $-\mathrm{CH}_{2} \mathrm{CH}_{3}$ & 883 & 451 & 331 & 416 & 216 & 201 \\
\hline YL-704 W & II & $-\mathrm{CH}_{2} \mathrm{CH}_{3}$ & $-\mathrm{CH}_{2} \mathrm{CH}\left(\mathrm{CH}_{3}\right)_{2}$ & 881 & 421 & 347 & 444 & 216 & 229 \\
\hline YL-704 W $\mathrm{W}_{2}$ & II & $-\mathrm{CH}_{2} \mathrm{CH}_{2} \mathrm{CH}_{3}$ & $-\mathrm{CH}_{2} \mathrm{CH}\left(\mathrm{CH}_{3}\right)_{2}$ & 895 & 435 & 347 & 444 & 216 & 229 \\
\hline Carbomycin B & II & $-\mathrm{CH}_{3}$ & $-\mathrm{CH}_{2} \mathrm{CH}\left(\mathrm{CH}_{3}\right)_{2}$ & 867 & 407 & 347 & 444 & 216 & 229 \\
\hline YL-704 $\mathrm{C}_{1}$ & III & $-\mathrm{CH}_{2} \mathrm{CH}_{3}$ & $-\mathrm{CH}_{2} \mathrm{CH}_{3}$ & 913 & 481 & 347 & 416 & 216 & 201 \\
\hline YL-704 $\mathrm{C}_{3}$ & III & $-\mathrm{CH}_{2} \mathrm{CH}_{3}$ & $-\mathrm{CH}_{2} \mathrm{CH}\left(\mathrm{CH}_{3}\right)_{2}$ & 941 & 481 & 347 & 444 & 216 & 229 \\
\hline YL-704 $\mathrm{C}_{4}$ & III & $-\mathrm{CH}_{3}$ & $-\mathrm{CH}_{2} \mathrm{CH}\left(\mathrm{CH}_{3}\right)_{2}$ & 927 & 467 & 347 & 444 & 216 & 229 \\
\hline $\begin{array}{l}\text { Dehydro } \\
\text { YL-704 } C_{1}\end{array}$ & IV & $-\mathrm{CH}_{2} \mathrm{CH}_{3}$ & $-\mathrm{CH}_{2} \mathrm{CH}_{3}$ & 869 & 437 & 363 & 416 & 216 & 201 \\
\hline Carbomycin A & IV & $-\mathrm{CH}_{3}$ & $-\mathrm{CH}_{2} \mathrm{CH}\left(\mathrm{CH}_{3}\right)_{2}$ & 883 & 423 & 363 & 444 & 216 & 229 \\
\hline
\end{tabular}

$\mathrm{M}^{+}$; Molecular ion, $\mathrm{AGL}^{+}$; Aglycone ion, ADS+; Acyldisaccharide ion, AMA+; Acetyl mycaminose ion, $\mathrm{AM}^{+} ; \mathrm{Acyl}$ mycarose ion. 
As the result, the propionyl function was present in YL-704 $\mathrm{C}_{1}$ and $\mathrm{C}_{3}$, the acetyl function did in YL-704 $\mathrm{C}_{4}$, at the $\mathrm{C}-3$ position of the aglycone, respectively.

The structures of all these minor components were elucidated. The diagnostic fragmentation peaks of their acetates were summarized in Table 1 .

\section{Experimental}

General Method

Melting points are uncorrected. IR spectra were measured with a Hitachi IR 215 and EPI 32 spectrometer. UV spectra were measured with a Hitachi 323 spectrophotometer. NMR- ${ }^{1} \mathrm{H}$ spectra were measured at $100 \mathrm{MHz}$ with a JNM $4 \mathrm{H}-100$ and a PS 100 spectrometer. Mass spectra were measured with a Hitachi RMU $7 \mathrm{~L}$ high resolution mass spectrometer. High resolution mass spectra were measured with a CEC-21 $110 \mathrm{~B}$ high resolution mass spectrometer. Thin-layer chromatography was employed for the detection of the course of reactions and the purity of the products, developed over silica gel $\mathrm{GF}_{254}$ (Merck) and alumina (Woelm) with benzene-acetone system. The chromatograms were visualized by heating at $120^{\circ} \mathrm{C}$ after spraying $40 \% \mathrm{H}_{2} \mathrm{SO}_{4}$.

Acetates of Minor Components

The acetates of all minor components were prepared with pyridine and acetic anhydride $(1: 1, \mathrm{v} / \mathrm{v})$ at room temperature overnight. After isolating of them by column chromatography on silicic acid (Mallinckrodt) with benzene containing $10 \%$ acetone, the acetates were recrystallized from ethylacetate- $n$-hexane. Their m. p. and elemental analyses were depicted in Table 2.

Oxidation of YL-704 $\mathrm{A}_{1}$ with $\mathrm{MnO}_{2}$

YL-704 $\mathrm{A}_{1}(100 \mathrm{mg})$ was dissolved in $5 \mathrm{ml} \mathrm{CHCl}{ }_{3}$ and added $5 \mathrm{~g}$ active $\mathrm{MnO}_{2}$. After 20hour stirring at room temperature, the oxidant was filtered off and washed successfully with $\mathrm{CHCl}_{3}$. Chloroform layer was dried and the residue was chromatographed over silica gel with the benzene-acetone $(3: 1)$ system. Fraction Nos. $8 \sim 25$ were collected and concentrated to dryness. The product was recrystallized from benzene- $n$-hexane (Yield $73 \mathrm{mg}$ ). m. p. 159 $160^{\circ} \mathrm{C}$.

$$
\begin{aligned}
& \text { Anal. calcd. for } \mathrm{C}_{43} \mathrm{H}_{68} \mathrm{NO}_{15} \text { : C 61.50, } \mathrm{H} 8.22, \mathrm{~N} 1.67 \\
& \text { Found: } \quad \text { C } 61.69, \mathrm{H} 8.30, \mathrm{~N} 1.65
\end{aligned}
$$

This product showed the UV maximum at $280 \mathrm{~nm}(\log \varepsilon 4.37)$ and identical with YL-704 $\mathrm{W}_{1}$ by IR, NMR and TLC.

\begin{tabular}{|c|c|c|c|c|c|c|c|c|}
\hline \multirow{2}{*}{ Acetates } & \multirow{2}{*}{$\mathrm{m} \cdot \mathrm{p} \cdot\left({ }^{\circ} \mathrm{C}\right)$} & \multirow{2}{*}{ Formulae } & \multicolumn{3}{|c|}{ Calcd. (\%) } & \multicolumn{3}{|c|}{ Found $(\%)$} \\
\hline & & & $\mathrm{C}$ & $\mathrm{H}$ & $\mathrm{N}$ & $\mathrm{C}$ & $\mathrm{H}$ & $\mathrm{N}$ \\
\hline Acetyl YL-704 W & $188 \sim 189$ & $\mathrm{C}_{45} \mathrm{H}_{71} \mathrm{NO}_{18}$ & 61.35 & 8.13 & 1.59 & 61.51 & 8.19 & 1.59 \\
\hline Acetyl YL-704 W & $156 \sim 157$ & $\mathrm{C}_{40} \mathrm{H}_{73} \mathrm{NO}_{18}$ & 61.73 & 8.22 & 1.57 & 61.98 & 8.40 & 1.59 \\
\hline Diacetyl YL-704 $\mathrm{A}_{2}$ & $115 \sim 117$ & $\mathrm{C}_{47} \mathrm{H}_{75} \mathrm{NO}_{17}$ & 60.97 & 8.11 & 1.51 & 60.39 & 8.08 & 1.50 \\
\hline Diacetyl YL-704 $\mathrm{B}_{2}$ & $124 \sim 126$ & $\mathrm{C}_{45} \mathrm{H}_{71} \mathrm{NO}_{17}$ & 60.20 & 7.91 & 1.56 & 60.22 & 8.05 & 1.54 \\
\hline Diacetyl YL-704 A & $125 \sim 126$ & $\mathrm{C}_{48} \mathrm{H}_{73} \mathrm{NO}_{17}$ & 60.64 & 8.08 & 1.54 & 60.37 & 8.33 & 1.51 \\
\hline Diacetyl YL-704 $B_{3}$ & $127 \sim 129$ & $\mathrm{C}_{44} \mathrm{H}_{69} \mathrm{NO}_{17}$ & 59.85 & 7.88 & 1.59 & 59.64 & 7.80 & 1.55 \\
\hline Diacetyl YL-704 $\mathrm{C}_{2}$ & $124 \sim 125$ & $\mathrm{C}_{44} \mathrm{H}_{69} \mathrm{NO}_{17}$ & 59.85 & $7 \cdot 88$ & 1.59 & 60.02 & 7.75 & 1.61 \\
\hline Diacetyl YL-704 $\mathrm{A}_{0}$ & $114 \sim 115$ & $\mathrm{C}_{48} \mathrm{H}_{77} \mathrm{NO}_{17}$ & 61.39 & 8.26 & 1.49 & 61.15 & 8.21 & 1.50 \\
\hline Diacetyl YL-704 C 1 & $102 \sim 104$ & $\mathrm{C}_{45} \mathrm{H}_{71} \mathrm{NO}_{18}$ & 59.85 & 7.83 & 1.53 & 59.72 & 7.82 & 1.54 \\
\hline Diacetyl YL-704 $\mathrm{C}_{3}$ & $107 \sim 109$ & $\mathrm{C}_{47} \mathrm{H}_{75} \mathrm{NO}_{18}$ & 59.99 & 8.04 & 1.49 & 60.37 & 8.26 & 1.50 \\
\hline Diacetyl YL-704 $\mathrm{C}_{4}$ & $104 \sim 106$ & $\mathrm{C}_{48} \mathrm{H}_{78} \mathrm{NO}_{18}$ & 59.60 & 7.94 & 1.51 & 59.88 & 7.84 & 1.53 \\
\hline
\end{tabular}

Table 2. Melting points and elemental analyses of acetates of minor components 
Dehydro YL-704 $\mathrm{C}_{1}$

The mixture of $50 \mathrm{mg}$ YL-704 $\mathrm{C}_{1}$ and $2 \mathrm{~g} \mathrm{MnO}_{2}$ was stirred in $\mathrm{CHCl}_{3}$ at room temperature for 20 hours. After filtration of $\mathrm{MnO}_{2}$, chloroform layer was evaporated to yield the crude powder. The crude product was chromatographed over silica gel by benzene-acetone $(2: 1)$. The corresponding fractions were collected and evaporated. By the crystallization in benzene$n$-hexane, coloress prisms were obtained (Yield $31 \mathrm{mg}$ ). m. p. $128 \sim 130^{\circ} \mathrm{C}$.

$\begin{array}{ll}\text { Anal. Calcd. for } \mathrm{C}_{41} \mathrm{H}_{65} \mathrm{NO}_{18}: & \mathrm{C} 59.54, \mathrm{H} 7.92, \mathrm{~N} 1.70 \\ \text { Found: } & \text { C } 60.00, \mathrm{H} 7.76, \mathrm{~N} 1.68\end{array}$

UV $\lambda_{\max }(\mathrm{EtOH}) 239 \mathrm{~nm}(\log \varepsilon 4.13)$.

IR $\nu_{\max }$ (nujol) $3505,2720,1740,1635,1165,1060,975,910 \mathrm{~cm}^{-1}$.

\section{Acknowledgement}

We wish to express our thanks to Prof. Akira Tatematsu (Meijo University) for providing access to a mass spectrometer, to Prof. KoJ Y YMAKAwA (Science University of Tokyo) for the measurement of NMR spectra and to Dr. KEISHI KOTERA and his collaborators of Analytical Center of this company for the instrumental and elemental analyses.

\section{References}

1) Kinumaki, A ; I. Takamori, Y. Sugawara, N. Nagahama, M. Suzuki, Y. Egawa, M. Sakurazawa \& T. OKUDA: Studies on the macrolide antibiotic YL-704 complex. II. Isolation and physicochemical properties of YL-704 components. J. Antibiotics 27: 102 106, 1974

2) Suzuki, M.; I. Takamori, A. Kinumaki, Y. Sugawara \& T. OKuda: The structures of antibiotics YL-704 $\mathrm{C}_{1}, \mathrm{C}_{2}$ and $\mathrm{W}_{1}$. J. Antibiotics 24: 904 906, 1971

3) Suzuki, M.; I. Takamori, A. Kinumaki, Y. Sugawara \& T. Okuda: The structures of antibiotics YL-704 A and B. Tetrahedron Letters 1971: 435-438, 1971

4) Kinumaki, A.; I. Takamori, Y. Sugawara, M. Suzuki \& T. Okuda: Studies on the macrolide antibiotic YL-704 complex. III. The structures of new macrolide antibiotics YL-704 $\mathrm{A}_{1}$ and $\mathrm{B}_{1}$. J. Antibiotics 27: 107 116, 1974

5) a) Hochstein, F.A. \& K. Murai: Magnamycin B, a second antibiotic from Streptomyces halstedii. J. Am. Chem. Soc. 76: 5080 5083, 1954

b) Omura, S.; A. Nakagawa, M. Otani, T. Hata, H. Ogura \& K. Furuhata: Structure of the spiramycins (foromacidines) and their relationship with the leucomycins and carbomycins (Magnamycins). J. Am. Chem. Soc. 91: 3401 3404, 1969

6) Omura, S.; M. Katagiri, H. Ogura \& T. Hata: The chemistry of leucomycins. III. Structure and stereochemistry of leucomycin $\mathrm{A}_{3}$. Chem. Pharm. Bull. 16: 1181 1186, 1968

7) Omura, S.; M. Katagiri \& T. Hata: The chemistry of leucomycins. VI. Structures of leucomycin $\mathrm{A}_{4}, \mathrm{~A}_{5}, \mathrm{~A}_{8}, \mathrm{~A}_{7}, \mathrm{~A}_{8}$ and $\mathrm{A}_{9}$. J. Antibiotics 21: 272 278, 1968

8) Machida, I.; S. Shiotsu, K. Yokota, S. Makino, G. Kawaguchi \& K. Honda: Espinomycins. Presented at 178 th Meeting of Japan Antibiotics Research Association. March 26, 1971

9) a) Muroi, M.; M. Izawa \& T. Kishi: Structures of maridomycin I, III, IV, V and VI, macrolide antibiotics. Experientia 28: 129 131, 1972

b) Muror, M.; M. Izawa, H. Ono, E. Higashide \& T Kishi: Isolation of maridomycins and structure of maridomycin. II. Experientia 28: 501 502, 1972

10) a) Woodward, R.B.: Struktur und Biogeneses der Macrolide, eine neue Klasse von Naturstoffen. Angew. Chem. 69: 50 58, 1957

b) Woodward, R.B.; L.S. Weiler \& P.C. Dutta: The structure of magnamycin. J. Am. Chem. Soc. 87: 4662 4663, 1965 